Article

\title{
Emphasizing the Operational Role of a Novel Graphene-Based Ink into High Performance Ternary Organic Solar Cells
}

\author{
Minas M. Stylianakis ${ }^{1, *,+}$ (D) Dimitrios M. Kosmidis ${ }^{1,+} \mathbb{\infty}$, Katerina Anagnostou ${ }^{1}$, \\ Christos Polyzoidis ${ }^{1}$, Miron Krassas ${ }^{1,2}$, George Kenanakis ${ }^{3}(D)$, George Viskadouros ${ }^{1,4}{ }^{(D)}$, \\ Nikolaos Kornilios ${ }^{1}$, Konstantinos Petridis ${ }^{1,5}$ and Emmanuel Kymakis ${ }^{1, *(D)}$ \\ 1 Department of Electrical \& Computer Engineering, Hellenic Mediterranean University (HMU), \\ Estavromenos, 71410 Heraklion, Greece; kosdimitris@hmu.gr (D.M.K.); katerinanag@hmu.gr (K.A.); \\ polyzoidis@hmu.gr (C.P.); kmiron@hmu.gr (M.K.); viskadouros@hmu.gr (G.V.); kornil@hmu.gr (N.K.); \\ c.petridischania@gmail.com (K.P.) \\ 2 Department of Materials Science and Technology, University of Crete, 71003 Heraklion, Greece \\ 3 Institute of Electronic Structure and Laser, Foundation for Research and Technology-Hellas, N. Plastira 100, \\ 70013 Heraklion, Greece; gkenanak@iesl.forth.gr \\ 4 Department of Mineral Resources Engineering, Technical University of Crete, 73100 Chania, Greece \\ 5 Department of Electronic Engineering, Hellenic Mediterranean University (HMU), 73132 Chania, Greece \\ * Correspondence: stylianakis@hmu.gr (M.M.S.); kymakis@hmu.gr (E.K.); Tel.: +30-2810-379775 (M.M.S.) \\ + These authors contributed equally to this work.
}

Received: 27 November 2019; Accepted: 28 December 2019; Published: 2 January 2020

check for updates

\begin{abstract}
A novel solution-processed, graphene-based material was synthesized by treating graphene oxide (GO) with 2,5,7-trinitro-9-oxo-fluorenone-4-carboxylic acid (TNF-COOH) moieties, via simple synthetic routes. The yielded molecule $\mathrm{N}$-[(carbamoyl-GO)ethyl]-N'-[(carbamoyl)-(2,5,7-trinitro-9-oxo-fluorene)] (GO-TNF) was thoroughly characterized and it was shown that it presents favorable highest occupied molecular orbital (HOMO) and lowest unoccupied molecular orbital (LUMO) energy levels to function as a bridge component between the polymeric donor poly(\{4,8-bis[(2-ethylhexyl)oxy]benzo[1,2-b:4, 5-b']dithiophene-2,6-diyl\}\{3-fluoro-2-[(2-ethylhexyl)carbonyl] thieno[3,4-b]thiophenediyl\}) (PTB7) and the fullerene derivative acceptor [6,6]-phenyl- $\mathrm{C}_{71}$-butyric-acid-methylester $\left(\mathrm{PC}_{71} \mathrm{BM}\right)$. In this context, a GO-TNF based ink was prepared and directly incorporated within the binary photoactive layer, in different volume ratios ( $1 \%-3 \%$ ratio to the blend) for the effective realization of inverted ternary organic solar cells (OSCs) of the structure ITO/PFN/PTB7:GO-TNF:PC 71 BM/MoO $/ \mathrm{Ml}_{3} / \mathrm{Al}$ The addition of $2 \% v / v$ GO-TNF ink led to a champion power conversion efficiency (PCE) of $8.71 \%$ that was enhanced by $\sim 13 \%$ as compared to the reference cell.
\end{abstract}

Keywords: ternary organic solar cells; graphene ink; functionalization; air-processed; cascade effect; charge transfer

\section{Introduction}

Due to the highly increased global demand for low-cost energy generation over the last three decades, significant research efforts have been made towards the development and progress of organic solar cells (OSCs), in order to boost their competitiveness over silicon technology [1,2]. Owing to several attractive properties, including light weight, flexibility, low manufacturing costs, and compatibility with large-area processes, OSCs is considered as one of the most prominent photovoltaic technologies for sustainable energy production [3]. 
In this context, several polymeric donor:fullerene-based acceptor combinations have been flourished providing a rapid increase in the OSC devices efficiency over 9\% [4-7]. On top of that, very recently, alternative optimized architectures such as tandem structures, novel donors and non-fullerene acceptor design and synthesis, as well as ternary systems have escalated the performance of OSCs over $14 \%$ [8-11].

Unlike to the typical binary OSC configuration, that is based on a donor-acceptor bulk heterojunction (BHJ) blend, the ternary one contains a third component which can function as: (i) second donor, (ii) second acceptor, and (iii) non-volatile additive [12]. The operation of a ternary OSC device relies on one of the four existing dominant mechanisms including: (1) charge transfer, (2) Forster resonance energy transfer, (3) parallel-linkage, and (4) alloyed donor structure mechanism [12,13]. Thus, according to the above mechanisms, small molecules [14-18], polymers [19-21], dye molecules [22,23], graphene-based materials [24,25] or 2D materials [12,26,27] could be chosen and incorporated as additives within the binary active layer.

This study discusses for the first time the design and synthesis of a novel graphene-based material (GO-TNF) through simple chemical processes as well as its direct incorporation in ink form within the binary active layer (PTB7:PC 71 BM) for the realization of inverted ternary OSC devices. GO-TNF consists of graphene oxide (GO) as core and TNF side groups linked with ethylenediamine (EDA) aliphatic spacers. Since the energy levels of the synthesized graphene-based molecule and these of PTB7 and $\mathrm{PC}_{71} \mathrm{BM}$ perfectly match, GO-TNF ink was incorporated in different ratios ranging from $1 \%$ to $3 \%$. Upon the incorporation of GO-TNF, charge transfer operational mechanism dominated (cascade effect), while the photovoltaic performance was boosted in all ternary devices compared to the reference cell. The champion device, containing 2\% v/v GO-TNF ink, exhibited a significant enhancement by $\sim 13 \%$, leading to a power conversion efficiency (PCE) of $8.71 \%$. This increase is mainly due to the improvement of the nanomorphology between the donor:acceptor blend's interfaces, as well as to electron mobility enhancement.

\section{Materials and Methods}

\subsection{Materials}

Initially, 9-oxo-fluorene-4-carboxylic acid 97\%, 1,2-ethylenediamine (EDA) puriss. p.a., absolute, $\geq 99.5 \%$ (GC), graphite synthetic, $\mathrm{H}_{2} \mathrm{SO}_{4} 95-97 \%$, fuming $\mathrm{HNO}_{3} 70 \%, \mathrm{SOCl}_{2}$ ReagentPlus $>99 \%$, were purchased from Sigma Aldrich (Taufkirchen, Germany). PTB7 was purchased from Solaris Chem (Vaudreuil-Dorion, QC, Canada), while $\mathrm{PC}_{71} \mathrm{BM}$ and PFN were both purchased from Solenne BV (Groningen, The Netherlands). Finally, $\mathrm{MoO}_{3}$ and $\mathrm{Al}$ were bought from Kurt J. Lesker (East Sussex, UK), while the glass-ITO substrates were purchased from Naranjo Substrates (Groningen, The Netherlands).

\subsection{Materials' Synthetic Procedures}

The preparation of GO-TNF took place into several steps, as it is depicted in Figure 1 and analyzed in Appendix A. First, 9-oxo-fluorene-4-carboxylic acid was nitrated using a mixture of concentrated sulfuric acid $\left(\mathrm{H}_{2} \mathrm{SO}_{4}, 95-97 \%\right)$ and fuming nitric acid $\left(\mathrm{HNO}_{3}, 70 \%\right)$, yielding 2,5,7-trinitro-9-oxo-fluorene-4-carboxylic acid (TNF-COOH). Afterwards, the carboxyl group of TNF was chlorinated using thionyl-chloride $\left(\mathrm{SOCl}_{2}\right)$, to get 2,5,7-trinitro-9-oxo-fluorene-4-acyl-chloride (TNF-COCl). The linkage of TNF-COCl with 1,4-ethylenediamine (EDA) was held via a typical nucleophilic substitution reaction to obtain TNF-EDA. In the second parallel step, GO was prepared via a modified Hummers' method [28] and was subsequently acylated, using $\mathrm{SOCl}_{2}$ to get GO-COCl [25]. The final GO-TNF was extracted upon the coupling between GO-COCl and TNF-EDA through a nucleophilic substitution reaction. Finally, GO-TNF ink was prepared as described in the SI (see Appendix A). 


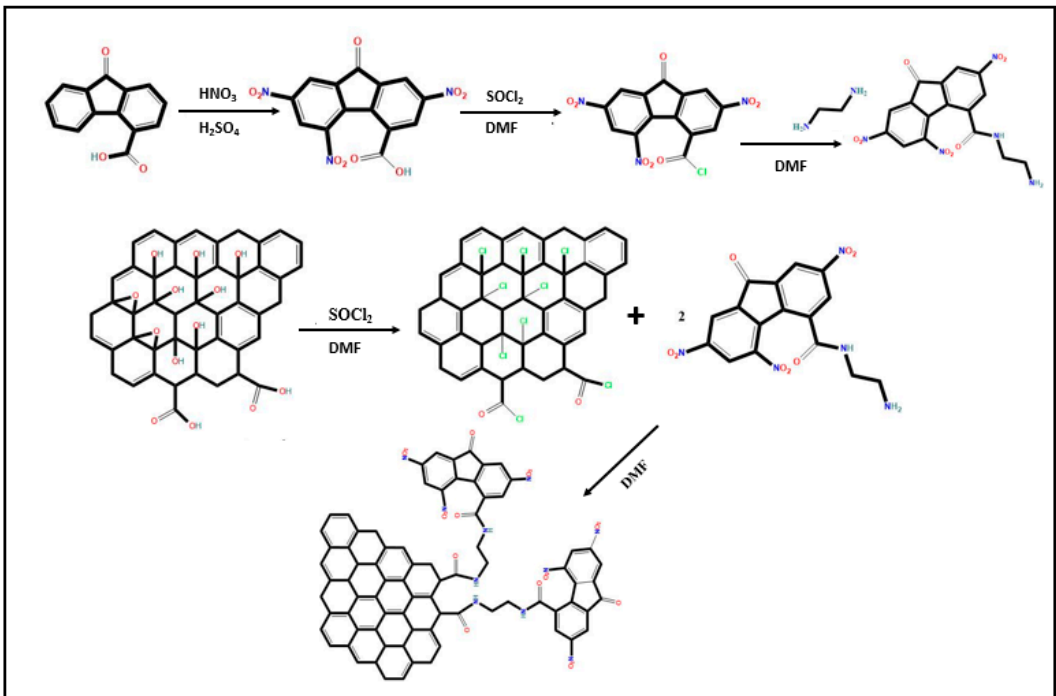

Figure 1. Schematic representation of the chemical synthetic procedure.

\subsection{OSC Device Fabrication}

All OSC devices were fabricated in a typical sandwich inverted geometry consisting of a bottom indium tin oxide (ITO) coated glass substrates electrode, poly [ $\left(9,9-\mathrm{bis}\left(3^{\prime}-(\mathrm{N}, \mathrm{N}\right.\right.$-dimethy -lamino)propyl)-2,7-fluorene)-alt-2,7-(9,9-dioctylfluorene)] (PFN) as the ETL, a PTB7:PC 71 BM BHJ thin film as the active layer, a $\mathrm{MoO}_{3}$ as the HTL and a top metal (Al) electrode. GO-TNF ink was directly incorporated within the binary photoactive layer, in ratios ranging from 1 to $3 \%$ ratio to the polymer for the fabrication of the ternary devices. The devices' fabrication in detail is reported in the SI. The schematic representation of the device and the respective energy level diagram are depicted in Figure 2.

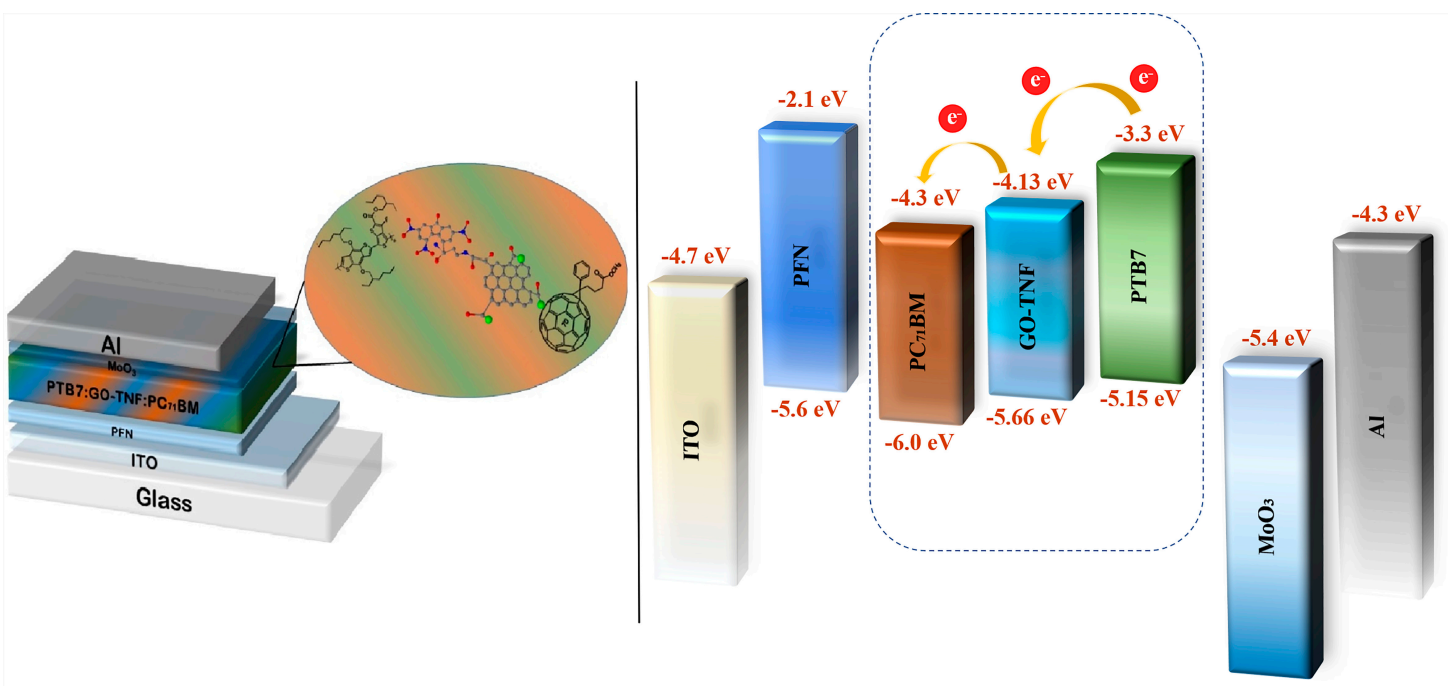

Figure 2. Schematic representation of the ternary OSC device (left) and energy levels diagram (right).

\subsection{Characterization Techniques}

ATR FT-IR (transmittance) experiments were carried out with a Bruker Vertex 70v FT-IR vacuum spectrometer equipped with a A225/Q Platinum ATR unit with single reflection diamond crystal which allows the infrared analysis of unevenly shaped solid samples and liquids through total reflection measurements, in a spectral range of $4000-700 \mathrm{~cm}^{-1}$. UV-vis absorption spectra were taken using a Shimadzu UV-2401 PC spectrophotometer, over the wavelength range of 270-800 nm. The photoluminescence (PL) measurements of the devices' active layers were carried out at room 
temperature and resolved by using a UV grating and a sensitive, calibrated and liquid $\mathrm{N}_{2}$-cooled CCD camera in the wavelength range from 600 to $950 \mathrm{~nm}$. The excitation source employed was a He-Cd CW laser at $325 \mathrm{~nm}$ with a full power of $P_{0}=35 \mathrm{~mW}$. Raman measurements were performed at room temperature using a Horiba LabRAM HR Evolution confocal micro-spectrometer, in backscattering geometry $\left(180^{\circ}\right)$, equipped with an air-cooled solid-state laser operating at $532 \mathrm{~nm}$ with $100 \mathrm{~mW}$ output power. The laser beam was focused on the samples using a 10× Olympus microscope objective (numerical aperture of 0.25 ), providing a $\sim 55 \mathrm{~mW}$ power on each sample. XRD patterns were collected on a Panalytical Expert Pro X-ray diffractometer, using $\mathrm{Cu} \mathrm{K}_{\alpha}$ radiation $(\lambda=1.5406 \AA)$. Thermogravimetric analysis (TGA) was performed on 5-10 mg samples over the temperature range from 40 to $800^{\circ} \mathrm{C}$ at a heating rate of $10^{\circ} \mathrm{C} /$ min utilizing a Perkin-Elmer Diamond Pyris model under $\mathrm{N}_{2}$ atmosphere. The morphology of the surfaces was examined with an Atomic Force Microscope (Park Systems XE7, Park Systems Corporate Headquarters, Suwon, Korea). SEM images were taken through a JEOL JSM-7000F field emission scanning electron microscope. Cyclic voltammetry measurements were conducted on an Autolab PGSTAT302N. The photovoltaic performance of the devices was evaluated at room temperature within glove box (MBRAUN) conditions $\left(\left(\mathrm{O}_{2}<0.1 \mathrm{ppm}\right)\right.$, moisture-free $\left(\mathrm{H}_{2} \mathrm{O}<0.1 \mathrm{ppm}\right)$ ), and under standard illumination conditions with an Air Mass 1.5 Global (A.M. $1.5 \mathrm{G}$ ) solar simulator at an intensity of $1000 \mathrm{Wm}^{-2}$ using an Agilent B1500A Semiconductor Device Analyzer, calibrated through a reference monocrystalline silicon solar cell supplied by Newport Corporation. The external quantum efficiency (EQE) measurements were conducted immediately after device fabrication, using an integrated system (Enlitech, Taiwan) and a lock-in amplifier with a current preamplifier, under short-circuit conditions. To enhance the credibility of our measurements, the solar simulator (a Xenon lamp) spectrum was calibrated using a monocrystalline photodetector of known spectral response. OSC devices were measured using a Xe lamp and an optical chopper at low frequencies $(\sim 200 \mathrm{~Hz})$ in order to maximize the sound/noise $(S / N)$ ratio. At least ten identical devices with six photovoltaics cells each were fabricated so that the reproducibility of the $J-V$ characteristics is ensured.

\section{Results and Discussions}

\subsection{ATR FT-IR Spectroscopy}

ATR FT-IR spectra of GO and GO-TNF, in powder form, are presented in Figure 3. Pristine GO (black line) shows a broad and strong peak at $3390 \mathrm{~cm}^{-1}$, which is attributed to O-H stretching vibration of the $\mathrm{OH}$ - moieties. Furthermore, stretching vibration of $\mathrm{C}=\mathrm{O}$ moieties is appeared at $1706 \mathrm{~cm}^{-1}$, while the remaining graphitic domains $(C=C)$ stretching vibration are shown at $1568 \mathrm{~cm}^{-1}$. In addition, $\mathrm{C}-\mathrm{O}-\mathrm{H}$ bending vibration due to $\mathrm{COOH}$ groups are presented at $1394 \mathrm{~cm}^{-1}$. The peaks at $1143 \mathrm{~cm}^{-1}$ and $1027 \mathrm{~cm}^{-1}$ represent $\mathrm{C}-\mathrm{OH}$ stretching vibration of the hydroxide domains and the stretching vibration of C-O-C groups, respectively. On the other hand, GO-TNF (red line), exhibits a broad peak of low intensity at $3331 \mathrm{~cm}^{-1}$, indicating a N-H stretching vibration. Next, a peak at $1697 \mathrm{~cm}^{-1}$ is attributed to $\mathrm{C}=\mathrm{O}$ stretching vibration deriving from the carbonyl moiety of trinitrofluorenone. Moreover, two peaks occurred at $1652 \mathrm{~cm}^{-1}$ and $1575 \mathrm{~cm}^{-1}$ are due to amidic $\mathrm{C}=\mathrm{O}$ stretching vibration. $\mathrm{NO}_{2}$ asymmetric and symmetric stretch vibrations are shown at $1525 \mathrm{~cm}^{-1}$ and $1334 \mathrm{~cm}^{-1}$, respectively, as well as the peak at $1446 \mathrm{~cm}^{-1}$ corresponds to the aliphatic a- $\mathrm{CH}_{2}$ bending vibration of ethylenediamine moiety. Finally, C-N stretching vibration of the ethylene diamine moieties appears at $1105 \mathrm{~cm}^{-1}$. ATR FT-IR spectra of the intermediate TNF and EDA-TNF are reported in the SI. 


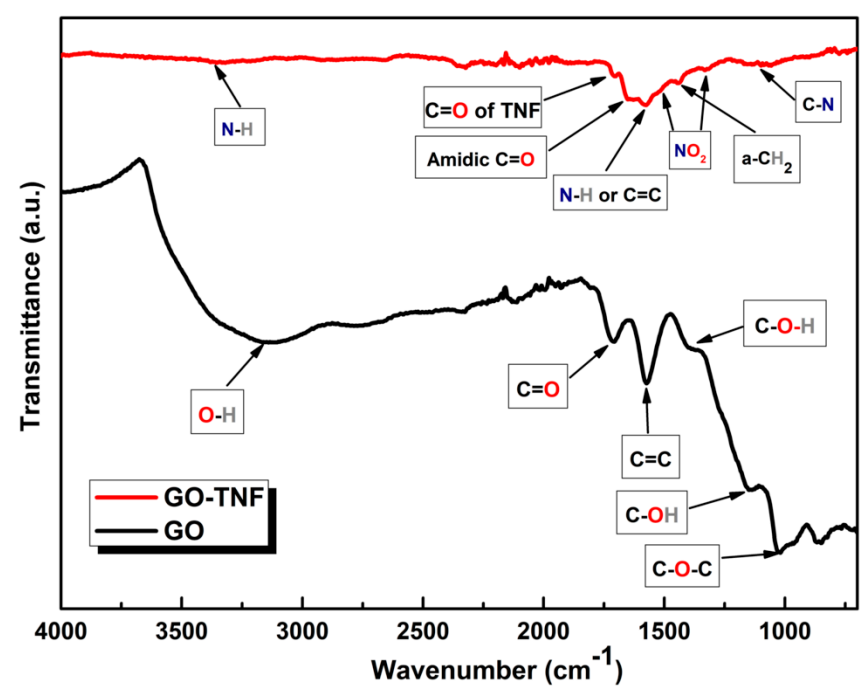

Figure 3. ATR FT-IR spectra of graphene oxide (GO) (black line) and GO-TNF (red line) in transmission mode.

\subsection{UV-Visible Measurements}

In Figure 4, UV-vis spectra of GO and GO-TNF in solid state are presented. Due to the strong attachment of TNF moieties to the edges of the lattice of GO, the absorption spectrum of GO-TNF is broader than that of the pristine GO, exhibiting a shoulder at $\sim 365 \mathrm{~nm}$. This fact indicates that there is a strong interaction between the GO lattice and TNF moieties, which is mainly attributed to the enhanced electron delocalization caused by TNF [24].

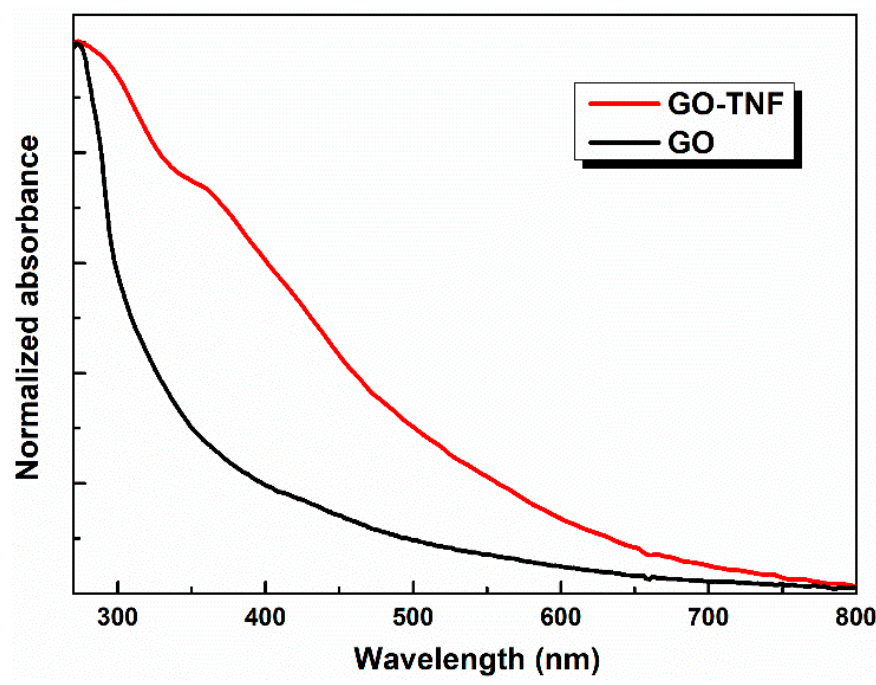

Figure 4. UV-vis spectra of GO (black line) and GO-TNF (red line).

\subsection{Raman Spectroscopy}

Raman spectra of GO and GO-TNF are shown in Figure 5. No shift is observed for both D and G peaks of GO compared to the respective ones of GO-TNF; D bands occurred at $1340 \mathrm{~cm}^{-1}$, while G bands at $\sim 1580 \mathrm{~cm}^{-1}$. However, a difference in the relative intensity ratio $\left(\mathrm{I}_{\mathrm{D}} / \mathrm{I}_{\mathrm{G}}\right)$ was observed from 0.92 for GO to 1.04 for GO-TNF, indicating that the linking between GO and TNF increased disorder and defects in the graphitic lattice [25]. 


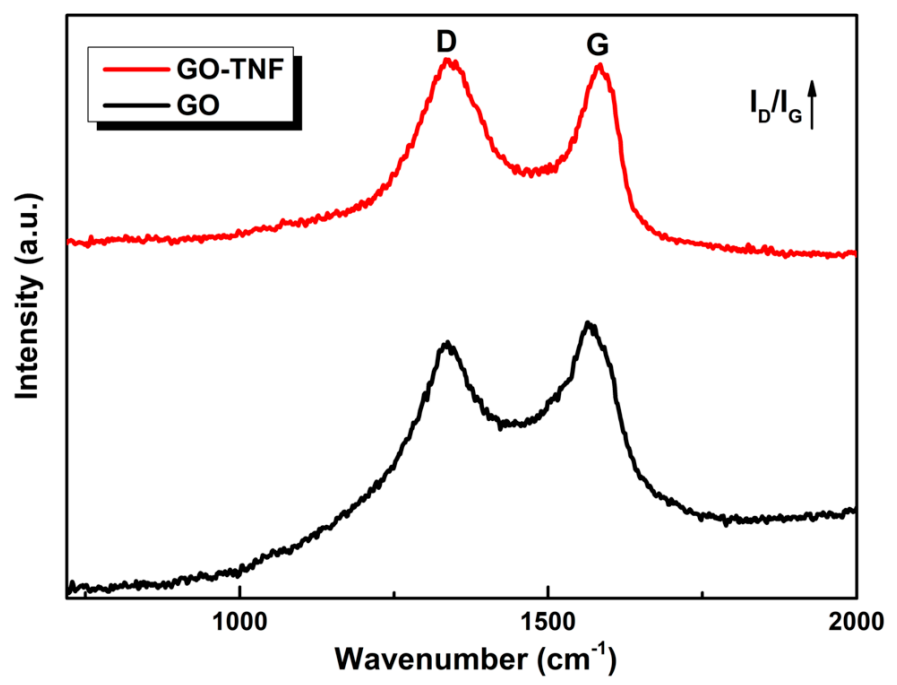

Figure 5. Raman spectra of GO and GO-TNF.

\subsection{Photoluminescence (PL) Spectroscopy}

Photoluminescence (PL) measurements were conducted to evaluate charge transfer mechanism upon the incorporation of GO-TNF within the active layer, and the respective PL spectra are depicted in Figure 6. In this context, PTB7 and PTB7:GO-TNF thin films were excited at $471 \mathrm{~nm}$ presenting an emission band around $760 \mathrm{~nm}$ corresponding to radiative decay of photogenerated excitons from the excited state to ground state [29]. When $2 \% v / v$ GO-TNF ink was added, PL intensity quenching is significant owing to the better energy offset between the LUMO levels of PTB7 and GO-TNF that enhances the charge transfer mechanism. In our case, the incorporation of GO-TNF ink with an optimum concentration of $2 \% v / v$, facilitates exciton dissociation at the PTB7:PC ${ }_{71} \mathrm{BM}$ interface thus leading to a higher number of electrons that can be collected by the cathode, which is in agreement with the champion current density value achieved so far $\left(17.65 \mathrm{~mA} \mathrm{~cm}^{-2}\right)$ [30].

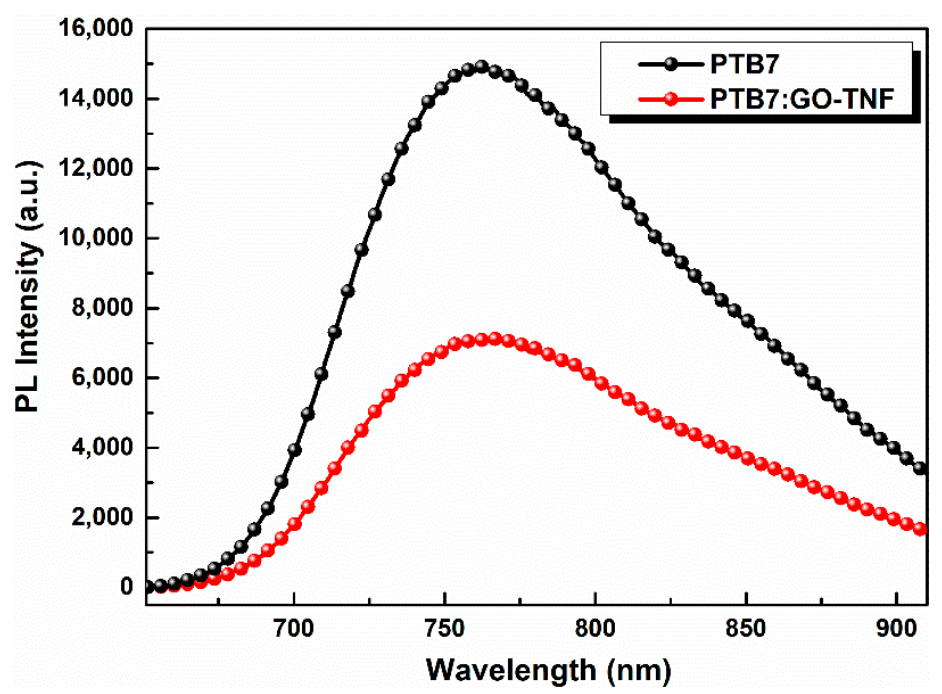

Figure 6. PL spectra of PTB7 (black) and PTB7:GO-TNF (2\%) (red).

\subsection{XRD Measurements}

The crystallinity of pristine GO and GO-TNF was investigated by X-ray diffraction (XRD) in a $2 \theta$ range from $5^{\circ}$ to $60^{\circ}$ (Figure 7 ). GO displays a narrow peak at $9.51^{\circ}$ which is attributed to the main reflection (002) of its stacks with an interlayer d-spacing of $\sim 8.2 \AA$, while a second weak peak appearing at $42.69^{\circ}$ is due to the turbostratic band of disordered carbon materials [31]. On the other 
hand, GO-TNF exhibits a broad peak at $24.99^{\circ}$ referring to (002) reflection with a slightly increased d-spacing of $9.1 \AA$ which is attributed to GO covalent bonding with TNF moieties.

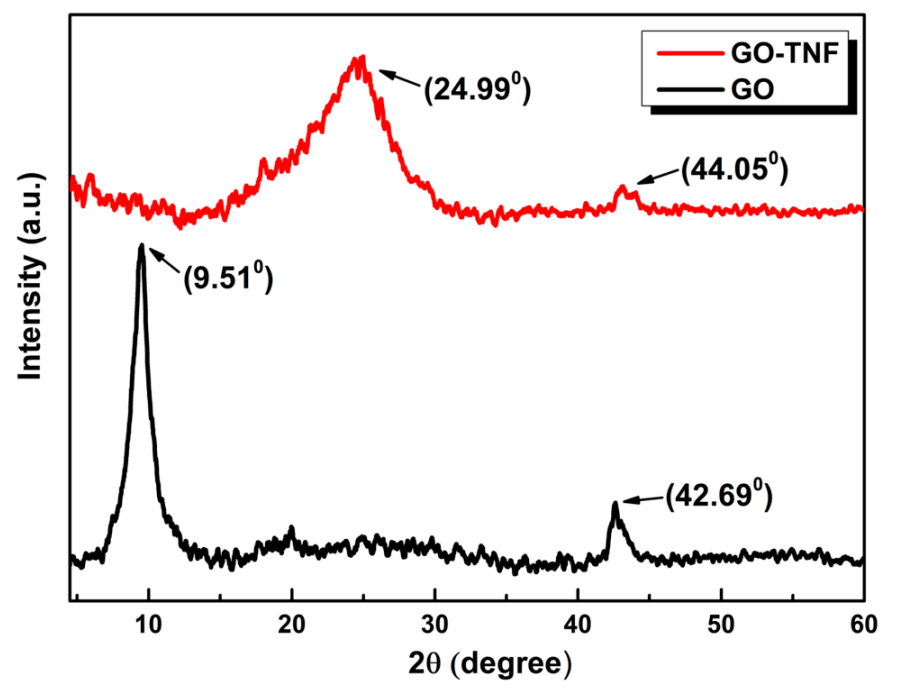

Figure 7. X-ray diffraction patterns of GO (black) and GO-TNF (red).

\subsection{Thermogravimetric (TGA) Analysis}

Figure 8 displays the TGA curves of GO and GO-TNF obtained under inert atmosphere with a heating rate of $10^{\circ} \mathrm{C} / \mathrm{min}$, while the maximum temperature limit was set at $800^{\circ} \mathrm{C}$. First, GO exhibited a moderate weight loss of $5 \%$ at a $210{ }^{\circ} \mathrm{C}$, which was followed by a steep weight loss of $37 \%$ at about $270{ }^{\circ} \mathrm{C}$ due to oxygen functional groups' pyrolysis. Its total mass loss was $40 \%$ at $800{ }^{\circ} \mathrm{C}$. On the other hand, GO-TNF presented an improved thermal stability when compared to GO, since the total loss did not exceed $22 \%$ of its initial weight. The improved thermal stability of GO-TNF was attributed to the successful amide bond formation between GO and TNF that enhances thermal stability [32].

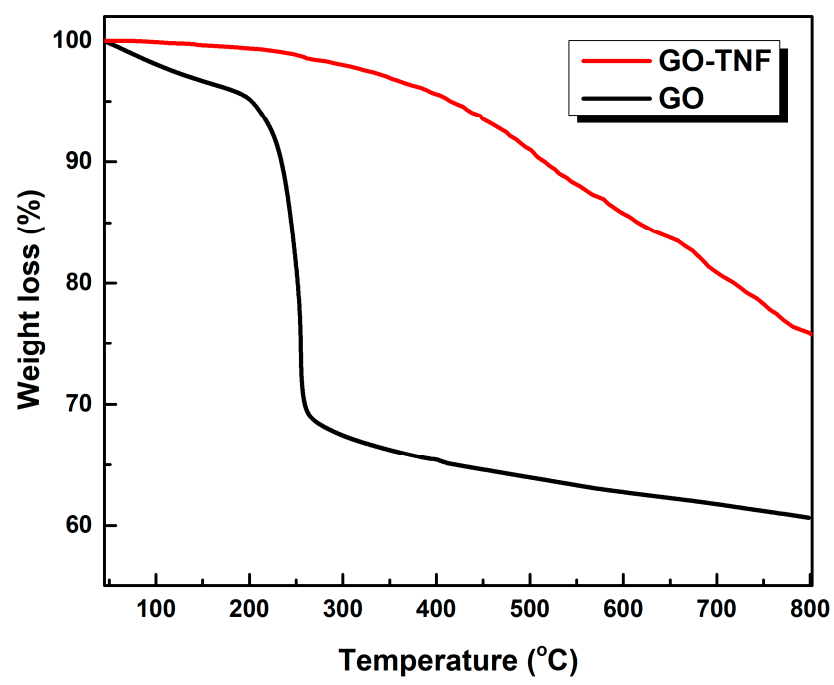

Figure 8. TGA curves of GO (black) and GO-TNF (red) taken under $\mathrm{N}_{2}$ atmosphere and $10^{\circ} \mathrm{C} / \mathrm{min}$ heating rate.

\subsection{Cyclic Voltammetry Measurements}

To determine the energy levels of GO-TNF, cyclic voltammetry measurements were carried out using an electrolytic solution of TBAPF6 in $\mathrm{CH}_{3} \mathrm{CN} 0.1 \mathrm{M}$, with a scan rate of $10 \mathrm{mVs}^{-1}$, between the 
potential sweep window of $-2 \mathrm{~V}$ to $+2 \mathrm{~V}$, as demonstrated in Figure 9. The energy HOMO and LUMO levels of GO-TNF were calculated using the empirical relations below [33]:

$$
\begin{aligned}
& \mathrm{E}_{\mathrm{HOMO}}=-\left(\mathrm{E}_{(\text {onset,ox vs } \mathrm{Fc}+) \mathrm{Fc}]}+5.1\right)(\mathrm{eV}) \\
& \mathrm{E}_{\mathrm{LUMO}}=-\left(\mathrm{E}_{(\text {onset,red vs } \mathrm{Fc}+) \mathrm{Fc}]}+5.1\right)(\mathrm{eV})
\end{aligned}
$$

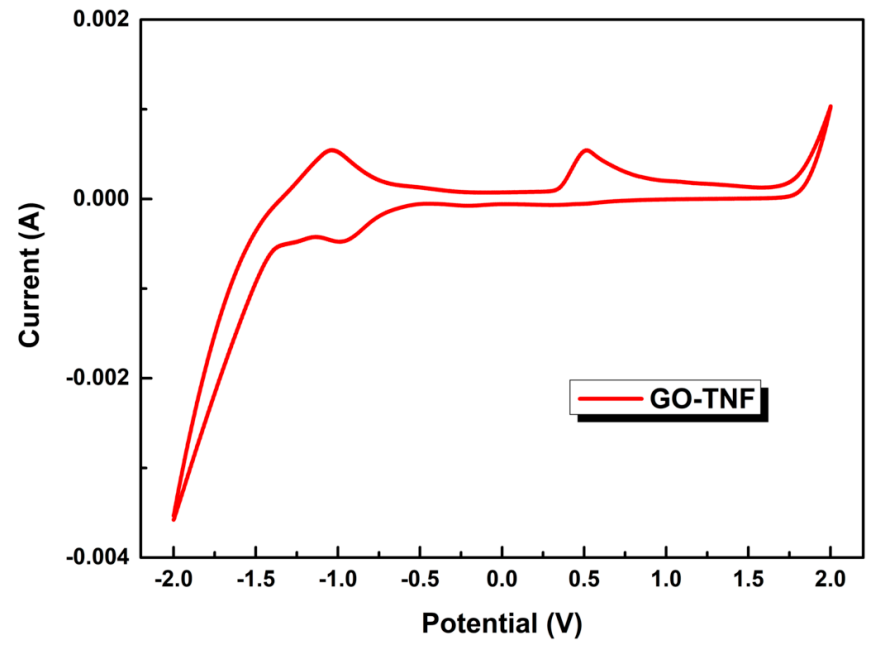

Figure 9. Cyclic voltammogram of GO-TNF.

The HOMO level was approximately $-5.66 \mathrm{eV}$ as calculated by the oxidation peak onset $0.53 \mathrm{~V}$, while its LUMO level was extracted from the onset of the reduction peak $(0.85 \mathrm{~V})$ and was $-4.13 \mathrm{eV}$.

\subsection{Microscopic Characterization}

The morphology of GO-TNF was examined using field emission scanning electron microscopy (FE-SEM). Representative SEM images of its flakes coated on silicon substrates are demonstrated in Figure S11. The size of the wrinkled GO-TNF flakes varies ranging from $100 \mathrm{~nm}$ to $1 \mu \mathrm{m}$, while it should be reported that no charging was observed during SEM imaging, thus indicating that the formed network was electrically conductive.

\subsection{Photovoltaic Performance Evaluation}

Several OSC devices were fabricated via the incorporation of GO-TNF ink within the binary PTB7:PC ${ }_{71} \mathrm{BM}$ photoactive layer (Figure 1 ) in various ratios $(1 \%, 2 \%$, and $3 \%$ ) and $J-V$ characteristic curves were exported to evaluate its operational role into device's photovoltaic (PV) performance (Figure 10). It is obvious that the presence of GO-TNF was beneficial, as stated below in Table 1.

Table 1. Photovoltaic characteristics summary of the OSC devices based on PTB7:GO-TNF:PC ${ }_{71}$ BM ternary blends ${ }^{\text {a }}$.

\begin{tabular}{cccccc}
\hline $\begin{array}{c}\text { GO-TNF } \\
\text { Content (\%) }\end{array}$ & $J_{s c}\left(\mathbf{m A} / \mathbf{c m}^{2}\right)$ & $\begin{array}{c}\text { Calc. } J_{s c} \\
\left(\mathbf{m A} / \mathbf{c m}^{2}\right)\end{array}$ & $\mathbf{V}_{\text {oc }}(\mathbf{V})$ & FF (\%) & PCE (\%) \\
\hline $\mathbf{0}$ & $16.20 \pm 0.45$ & 15.72 & $0.760 \pm 0.010$ & $61.8 \pm 0.7$ & $7.61 \pm 0.11$ \\
$\mathbf{1}$ & $16.54 \pm 0.54$ & 16.21 & $0.760 \pm 0.005$ & $63.0 \pm 0.4$ & $7.92 \pm 0.26$ \\
$\mathbf{2}$ & $17.21 \pm 0.44$ & 16.78 & $0.760 \pm 0.011$ & $64.0 \pm 0.1$ & $8.37 \pm 0.34$ \\
$\mathbf{3}$ & $16.53 \pm 0.35$ & 16.21 & $0.760 \pm 0.009$ & $62.4 \pm 0.6$ & $7.84 \pm 0.17$ \\
\hline
\end{tabular}

a The data is averaged from 10 identical devices with 6 cells each.

All ternary devices showed an improved performance, especially the device containing $2 \% v / v$ GO-TNF ink. In particular, the champion device exhibited a current density $\left(J_{s c}\right)$ of $17.65 \mathrm{~mA} / \mathrm{cm}^{2}$ and a 
power conversion efficiency (PCE) of $8.71 \%$ that show an improvement of $\sim 10 \%$ and $\sim 13 \%$ respectively when compared to the reference device.

To further confirm the experimental $J_{s c}$ improvement due to the incorporation of GO-TNF, external quantum efficiency measurements were conducted to determine the calculated $J_{\text {sc }}$. Figure 10 depicts the external quantum efficiency (EQE) curves of the reference, as well as the champion ternary OSC device incorporating 2\% v/v GO-TNF ink.

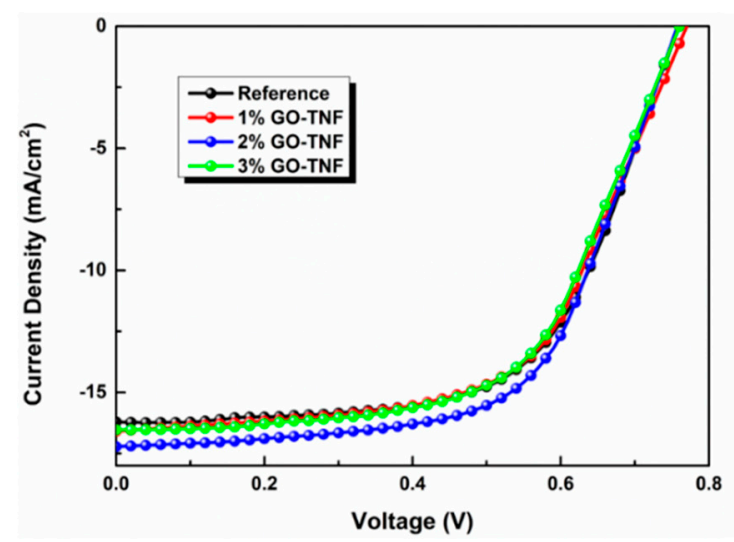

(a)

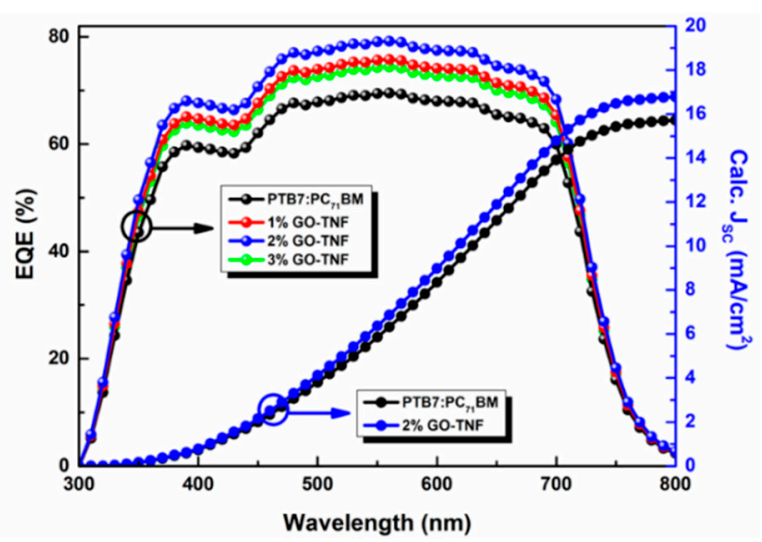

(b)

Figure 10. $J-V$ characteristics (a) and EQE curves (b) of the reference (PTB7:PC $71 \mathrm{BM})$ and the devices incorporating different GO-TNF ink content. The calculated $J_{s c}$ curves (inset in EQE) correspond to the reference and the champion device with $2 \%$ GO-TNF ink content.

It can be seen that the EQE enhancement is in full accordance to $J_{s c}$ increase, as calculated from the respective $J-V$ curves depicted in Figure 10a. In addition, the absence of any new peak is in agreement with the operational role of GO-TNF, which does not contribute in exciton generation but only in electron transfer, hence confirming the charge transfer mechanism (cascade effect). The accuracy of the PV measurements was checked, by calculating the $J_{S c}$ values of the OSCs from the integration of the EQE spectra. The calculated $J_{s c}$ was found to be $-15.72 \mathrm{~mA} \mathrm{~cm}{ }^{-2}$ and $-16.78 \mathrm{~mA} \mathrm{~cm}^{-2}$ for the binary and the $2 \%$ GO-TNF ink content ternary devices, respectively, which are within the standard deviation from the $J_{s c}$ obtained from the $J-V$ curves. It should be also noted that any concentration of GO-TNF ink higher than 3\% wt. resulted in a short circuit, probably due to the occurrence of local shunts. This undesired effect could be linked with the concentration of GO-TNF ink in the blend that becomes enough to allow a direct bridging with the ITO electrode.

To get a more accurate insight into the influence of GO-TNF blend into the charge transfer process in the ternary approach, hole-only and electron-only cells were fabricated to calculate the hole and electron mobility, respectively. Measurements were based on space charge limited current method. Hole-only cells and electron-only cells were fabricates using the architecture indium tin oxide ITO/PEDOT:PSS/PTB7:GO-TNF:PC 71 BM/MoO $/ \mathrm{Al}_{3}$ for holes and ITO/PFN/PCDTBT:GO-TNF:PC 71 BM/Ca/Al for electrons, respectively. The evaluation of the charge carrier mobilities was based on the Mott-Gurney equation [34]:

$$
J_{S C L C}=\frac{9}{8} \varepsilon_{r} \varepsilon_{0} \mu \frac{\left(V-V_{b i}\right)^{2}}{d^{3}}
$$

where $\varepsilon_{r}$ is the relative dielectric constant, $\varepsilon_{0}$ is the permittivity of free space, $\mu$ is the charge carrier mobility, $V$ is the applied voltage, $V_{b i}$ is the built-in potential, and $d$ is the active layer thickness.

Supplementary Figure 512 illustrates $J-V^{2}$ characteristics under dark conditions for (a) electron-only and (b) hole-only devices, respectively, where the black line refers to the control device (PTB7:PC 71 BM), while the red line corresponds to the champion ternary one PTB7:GO-TNF (2\%): PC 71 BM. According to $J-V^{2}$ characteristics, although hole mobility did not present any significant change upon the addition 
of GO-TNF, the respective electron mobility has shown a significant improvement, passing from $7.80 \times 10^{-5} \mathrm{~cm}^{2} \mathrm{~V}^{-1} \mathrm{~s}^{-1}$ to $9.93 \times 10^{-5} \mathrm{~cm}^{2} \mathrm{~V}^{-1} \mathrm{~s}^{-1}$ (Table 2). This improvement in electron mobility obviously originates from the presence of GO-TNF which has favourable energy levels, located between the energy levels of the donor and acceptor materials, respectively. Hence, the observed electrons' mobility enhancement is directly associated with the cascade effect facilitating electrons' transition from PTB7 to the ITO electrode [35].

In Appendix A, supplementary Figure S13 represents a simple one diode equivalent circuit model corresponding to the ternary OSC device incorporating 2\% GO-TNF ink. The diode " $\mathrm{D}$ " corresponds to the electrical equivalent of the optical losses at the surface of bulk heterojunction. " $R_{\mathrm{sh}}$ " represents the leakage and recombination losses whereas " $\mathrm{R}_{\mathrm{S}}$ " represents the sum of the internal resistance, including the resistance of the active layer and ohmic contact.

Due to photoluminescence, the generated excitons are diffused to the nearest D: A interface and are dissociated to form polaron-pairs. Polaron pairs can be either recombined or dissociated into free carriers and are subsequently extracted to the electrodes through a cascade-diffusion process. GO-TNF plays a key role in this cascade process, facilitating charge transfer from the polymer to the fullerene reducing the possibility of free carriers' recombination. This can be proven, by calculating the overall resistance at the maximum power point which represents the decrease of the overall resistance that derives from the higher recombination rate, resulting in larger $\mathrm{R}_{\mathrm{sh}}$ value (Supplementary Figure S14).

Table 2. Hole and electron mobilities of PTB7:PC 71 BM and ternary blend PTB7:GO-TNF:PC 71 BM *

\begin{tabular}{cccc}
\hline Active Layer & $\mu_{\mathbf{h}}\left(\mathbf{c m}^{\mathbf{2}} \mathbf{V}^{-\mathbf{1}} \mathbf{s}^{-\mathbf{1}}\right)$ & $\mu_{\mathrm{e}}\left(\mathrm{cm}^{\mathbf{2}} \mathbf{V}^{-\mathbf{1}} \mathbf{s}^{-\mathbf{1}}\right)$ & Ratio $\left(\mu_{\mathrm{h}} / \mu_{\mathrm{e}}\right)$ \\
\hline $\begin{array}{c}\text { PTB7:PC } \\
\text { (reference) }\end{array}$ & $1.28 \times 10^{-4}$ & $7.80 \times 10^{-5}$ & 1.64 \\
$\mathbf{1 \%}$ GO-TNF & $1.31 \times 10^{-4}$ & $8.71 \times 10^{-5}$ & 1.50 \\
$\mathbf{2 \%}$ GO-TNF & $1.39 \times 10^{-4}$ & $9.93 \times 10^{-5}$ & 1.39 \\
$\mathbf{3 \%}$ GO-TNF & $1.34 \times 10^{-4}$ & $8.03 \times 10^{-5}$ & 1.67 \\
\hline
\end{tabular}

* The data were averaged from 10 identical devices with 6 cells each.

\subsection{Morphology Characterization of the Active Layer}

The morphology of the reference PTB7:PC $71 \mathrm{BM}$ as well as the champion ternary blend $(2 \%)$ surfaces were both examined by atomic force microscopy (AFM), with a scan size of $1 \mathrm{~mm}$ by $1 \mathrm{~mm}$, as displayed in Figure 11. The said ternary active layer exhibited a slightly smoother surface than the binary one, giving a root-mean-square (RMS) roughness of $1.15 \mathrm{~nm}$ and $1.22 \mathrm{~nm}$, respectively. The fact that the morphology was improved upon the incorporation of $2 \%$ GO-TNF is in full accordance to $J_{s c}$ increase, indicating that the possibility of energetic disorders formation is smaller in case of the ternary device. On the other hand, $V_{o c}$ slightly changed upon the addition of GO-TNF, which is normal, since GO-TNF was incorporated in very low concentrations that cannot significantly affect $V_{o c}$ values.

a) $\mathrm{mm}$

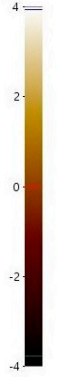

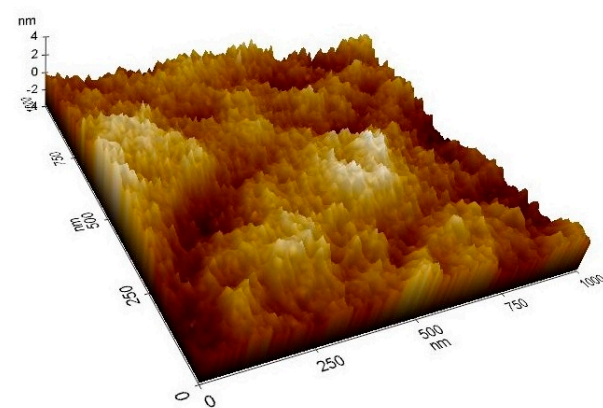

b) $\stackrel{m}{4 .}$

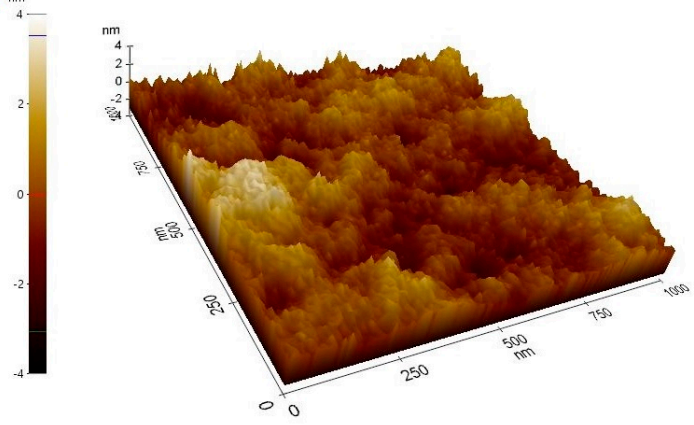

Figure 11. AFM images of (a) the reference PTB7:PC ${ }_{71} \mathrm{BM}$ active layer and (b) the champion ternary device containing $2 \%$ of GO-TNF ink. 


\section{Conclusions}

Herein, we reported the synthesis and characterization of a new graphene-trinitrofluorenone derivative, named GO-TNF, as well as its operational role as the cascade material between the LUMO energy levels of PTB7 and PC 71 BM, in efficient ternary OSCs. Due to its ideal energy levels, it was directly incorporated, as the third component, within the binary photoactive layer providing a significant improvement in current density of the champion device ( $2 \% v / v$ GO-TNF ink) by $\sim 10 \%$. Respectively, the PCE value of the same device was higher by $\sim 13 \%$, leading to a champion efficiency of $8.71 \%$. Our efforts proved that the rational design of graphene-based molecules could provide the opportunity for novel materials synthesis with tunable properties to be incorporated as additives, even as interlayers into organic, as well as hybrid solar cells, thus contributing to the realization of new generation high performance PV systems.

Supplementary Materials: The following are available online at http://www.mdpi.com/2079-4991/10/1/89/s1, Figure S1: The reaction mechanism of the nitration of 9-oxo-fluorene-4-carboxylic acid, Figure S2: The reaction mechanism of acyl chloride synthesis, Figure S3: The reaction mechanism of the amide bond formation, Figure S4: Schematic of 9-oxo-4-carboxyl-fluorenone nitration, Figure S5: ATR FT-IR spectrum of TNF-COOH, Figure S6: Schematic representation of TNF-COCl synthesis, Figure S7: The reaction representation of TNF-EDA synthesis, Figure S8: ATR FT-IR spectrum of TNF-EDA, Figure S9: The reaction representation of GO-COCl preparation, Figure S10: (i) Schematic of the final reaction of GO-TNF, (ii) GO-COCl and TNF-EDA in powder form (a), setup of the reaction (b), GO-TNF in powder form (c), Figure S11: FE-SEM images of GO-TNF, Figure S12: $J-V^{2}$ characteristics of the fabricated (a) electron-only and (b) hole-only devices, Figure S13: The one diode equivalent circuit model corresponding to the ternary OSC device incorporating 2\% GO-TNF ink, Figure S14: The effect of shunt resistance.

Author Contributions: Conceptualization, M.M.S. and D.M.K.; Methodology, M.M.S., D.M.K. and M.K.; Formal Analysis, M.M.S., C.P., G.K., G.V., N.K. and K.P.; Investigation, M.M.S. and D.M.K., Data Curation, M.M.S., K.A., M.K., G.K., G.V., N.K. and K.P.; Writing-Original Draft Preparation, M.M.S., D.M.K., K.A. and C.P.; Writing-Review and Editing, M.M.S., M.K., G.V. and K.P.; Supervision, M.M.S. and E.K.; Project Administration, M.M.S. Funding Acquisition, M.M.S. All authors have read and agreed to the published version of the manuscript.

Funding: This research is co-financed by Greece and the European Union (European Social Fund-ESF) through the Operational Programme «Human Resources Development, Education and Lifelong Learning» in the context of the project "Reinforcement of Postdoctoral Researchers" (MIS-5001552), implemented by the State Scholarships Foundation (IKr), Grant No. 13992.

Acknowledgments: The authors would like to thank Aleka Manousaki for the FE-SEM images.

Conflicts of Interest: The authors declare no conflict of interest.

\section{Appendix A}

The synthetic procedure of GO-TNF and its intermediate stages, as well as explanations of experimental details to understanding and reproducing the research are available.

\section{References}

1. Inganäs, O. Organic Photovoltaics over Three Decades. Adv. Mater. 2018, 30, 1800388. [CrossRef] [PubMed]

2. Lee, C.; Lee, S.; Kim, G.U.; Lee, W.; Kim, B.J. Recent Advances, Design Guidelines, and Prospects of All-Polymer Solar Cells. Chem. Rev. 2019, 119, 8028-8086. [CrossRef] [PubMed]

3. Zhang, J.; Tan, H.S.; Guo, X.; Facchetti, A.; Yan, H. Material Insights and Challenges for Non-Fullerene Organic Solar Cells Based on Small Molecular Acceptors. Nat. Energy 2018, 3, 720-731. [CrossRef]

4. He, Z.; Zhong, C.; Huang, X.; Wong, W.Y.; Wu, H.; Chen, L.; Su, S.; Cao, Y. Simultaneous Enhancement of Open-Circuit Voltage, Short-Circuit Current Density, and Fill Factor in Polymer Solar Cells. Adv. Mater. 2011, 23, 4636-4643. [CrossRef]

5. He, Z.; Zhong, C.; Su, S.; Xu, M.; Wu, H.; Cao, Y. Enhanced power-conversion efficiency in polymer solar cells using an inverted device structure. Nat. Photon. 2012, 6, 591-595. [CrossRef]

6. Green, M.A.; Emery, K.; Hishikawa, Y.; Warta, W.; Dunlop, E.D. Solar cell efficiency tables (Version 45). Prog. Photovolt. Res. Appl. 2013, 21, 1-11. [CrossRef]

7. Li, G.; Zhu, R.; Yang, Y. Polymer solar cells. Nat. Photon. 2012, 6, 153-161. [CrossRef] 
8. Meng, L.; Zhang, Y.; Wan, X.; Li, C.; Zhang, X.; Wang, Y.; Ke, X.; Xiao, Z.; Ding, L.; Xia, R.; et al. Organic and Solution-Processed Tandem Solar Cells with 17.3\% Efficiency. Science 2018, 361, 1094-1098. [CrossRef]

9. Yuan, J.; Zhang, Y.; Zhou, L.; Zhang, G.; Yip, H.L.; Lau, T.K.; Lu, X.; Zhu, C.; Peng, H.; Johnson, P.A.; et al. Single-Junction Organic Solar Cell with over 15\% Efficiency Using Fused-Ring Acceptor with Electron-Deficient Core. Joule 2019, 3, 1140-1151. [CrossRef]

10. Liu, T.; Luo, Z.; Chen, Y.; Yang, T.; Xiao, Y.; Zhang, G.; Ma, R.; Lu, X.; Zhan, C.; Zhang, M.; et al. A Nonfullerene Acceptor with a $1000 \mathrm{Nm}$ Absorption Edge Enables Ternary Organic Solar Cells with Improved Optical and Morphological Properties and Efficiencies over 15\%. Energy Environ. Sci. 2019, 12, 2529-2536. [CrossRef]

11. Liu, X.; Yan, Y.; Yao, Y.; Liang, Z. Ternary Blend Strategy for Achieving High-Efficiency Organic Solar Cells with Nonfullerene Acceptors Involved. Adv. Funct. Mater. 2018, 28, 1-20. [CrossRef]

12. Stylianakis, M.M.; Konios, D.; Petridis, C.; Kakavelakis, G.; Stratakis, E.; Kymakis, E. Ternary Solution-Processed Organic Solar Cells Incorporating 2D Materials. 2D Mater. 2017, 4, 042005. [CrossRef]

13. Gasparini, N.; Salleo, A.; McCulloch, I.; Baran, D. The Role of the Third Component in Ternary Organic Solar Cells. Nat. Rev. Mater. 2019, 4, 229-242. [CrossRef]

14. Song, X.; Gasparini, N.; Nahid, M.M.; Paleti, S.H.K.; Wang, J.L.; Ade, H.; Baran, D. Dual Sensitizer and Processing-Aid Behavior of Donor Enables Efficient Ternary Organic Solar Cells. Joule 2019, 3, 846-857. [CrossRef]

15. Seco, C.R.; Vidal-Ferran, A.; Misra, R.; Sharma, G.D.; Palomares, E. Efficient Non-Polymeric Heterojunctions in Ternary Organic Solar Cells. ACS Appl. Energy Mater. 2018, 1, 4203-4210. [CrossRef]

16. Qin, R.; Guo, D.; Li, M.; Li, G.; Bo, Z.; Wu, J. Perylene Monoimide Dimers Enhance Ternary Organic Solar Cells Efficiency by Induced D-A Crystallinity. ACS Appl. Energy Mater. 2019, 2, 305-311. [CrossRef]

17. Fu, H.; Li, C.; Bi, P.; Hao, X.; Liu, F.; Li, Y.; Wang, Z.; Sun, Y. Efficient Ternary Organic Solar Cells Enabled by the Integration of Nonfullerene and Fullerene Acceptors with a Broad Composition Tolerance. Adv. Funct. Mater. 2019, 29, 1-8. [CrossRef]

18. Cheng, P.; Li, Y.; Zhan, X. Efficient Ternary Blend Polymer Solar Cells with Indene-C60 Bisadduct as an Electron-Cascade Acceptor. Energy Environ. Sci. 2014, 7, 2005-2011. [CrossRef]

19. Lu, L.; Xu, T.; Chen, W.; Landry, E.S.; Lu, L. Ternary blend polymer solar cells with enhanced power conversion efficiency. Nat. Photon. 2014, 8, 716-722. [CrossRef]

20. Lu, L.; Chen, W.; Xu, T.; Yu, L. High-Performance Ternary Blend Polymer Solar Cells Involving Both Energy Transfer and Hole Relay Processes. Nat. Commun. 2015, 6, 1-7. [CrossRef]

21. Gasparini, N.; Lucera, L.; Salvador, M.; Prosa, M.; Spyropoulos, G.D.; Kubis, P.; Egelhaaf, H.J.; Brabec, C.J.; Ameri, T. High-Performance Ternary Organic Solar Cells with Thick Active Layer Exceeding 11\% Efficiency. Energy Environ. Sci. 2017, 10, 885-892. [CrossRef]

22. Ke, L.; Gasparini, N.; Min, J.; Zhang, H.; Adam, M.; Rechberger, S.; Forberich, K.; Zhang, C.; Spiecker, E.; Tykwinski, R.R.; et al. Panchromatic Ternary/Quaternary Polymer/Fullerene BHJ Solar Cells Based on Novel Silicon Naphthalocyanine and Silicon Phthalocyanine Dye Sensitizers. J. Mater. Chem. A 2017, 5, 2550-2562. [CrossRef]

23. Stylianakis, M.M.; Konios, D.; Viskadouros, G.; Vernardou, D.; Katsarakis, N.; Koudoumas, E.; Anastasiadis, S.H.; Stratakis, E.; Kymakis, E. Ternary Organic Solar Cells Incorporating Zinc Phthalocyanine with Improved Performance Exceeding 8.5\%. Dyes Pigm. 2017, 146, 408-413. [CrossRef]

24. Bonaccorso, F.; Balis, N.; Stylianakis, M.M.; Savarese, M.; Adamo, C.; Gemmi, M.; Pellegrini, V.; Stratakis, E.; Kymakis, E. Functionalized Graphene as an Electron-Cascade Acceptor for Air-Processed Organic Ternary Solar Cells. Adv. Funct. Mater. 2015, 25, 3870-3880. [CrossRef]

25. Stylianakis, M.M.; Konios, D.; Kakavelakis, G.; Charalambidis, G.; Stratakis, E.; Coutsolelos, A.G.; Kymakis, E.; Anastasiadis, S.H. Efficient Ternary Organic Photovoltaics Incorporating a Graphene-Based Porphyrin Molecule as a Universal Electron Cascade Material. Nanoscale 2015, 7, 17827-17835. [CrossRef] [PubMed]

26. Sygletou, M.; Tzourmpakis, P.; Petridis, C.; Konios, D.; Fotakis, C.; Kymakis, E.; Stratakis, E. Laser Induced Nucleation of Plasmonic Nanoparticles on Two-Dimensional Nanosheets for Organic Photovoltaics. J. Mater. Chem. A 2016, 4, 1020-1027. [CrossRef]

27. Kakavelakis, G.; Del Rio Castillo, A.E.; Pellegrini, V.; Ansaldo, A.; Tzourmpakis, P.; Brescia, R.; Prato, M.; Stratakis, E.; Kymakis, E.; Bonaccorso, F. Size-Tuning of WSe2 Flakes for High Efficiency Inverted Organic Solar Cells. ACS Nano 2017, 11, 3517-3531. [CrossRef] 
28. Stylianakis, M.M.; Viskadouros, G.; Polyzoidis, C.; Veisakis, G.; Kenanakis, G.; Kornilios, N.; Petridis, K.; Kymakis, E. Updating the Role of Reduced Graphene Oxide Ink on Field Emission Devices in Synergy with Charge Transfer Materials. Nanomaterials 2019, 9, 137. [CrossRef]

29. Nagarjuna, P.; Bagui, A.; Gupta, V.; Singh, S.P. A Highly Efficient PTB7-Th Polymer Donor Bulk Hetero-Junction Solar Cell with Increased Open Circuit Voltage Using Fullerene Acceptor CN-PC 70 BM. Org. Electron. 2017, 43, 262-267. [CrossRef]

30. Fan, R.; Huai, Z.; Sun, Y.; Li, X.; Fu, G.; Huang, S.; Wang, L.; Yang, S. Enhanced Performance of Polymer Solar Cells Based on PTB7-Th:PC 71 BM by Doping with 1-Bromo-4-Nitrobenzene. J. Mater. Chem. C 2017, 5, 10985-10990. [CrossRef]

31. Zhu, Y.; Murali, S.; Cai, W.; Li, X.; Suk, J.W.; Potts, J.R.; Ruoff, R.S. Graphene and Graphene Oxide: Synthesis, Properties, and Applications. Adv. Mater. 2010, 22, 3906-3924. [CrossRef] [PubMed]

32. Tang, X.Z.; Li, W.; Yu, Z.Z.; Rafiee, M.A.; Rafiee, J.; Yavari, F.; Koratkar, N. Enhanced thermal stability in graphene oxide covalently functionalized with 2-amino-4, 6-didodecylamino-1, 3, 5-triazine. Carbon 2011, 49, 1258-1265. [CrossRef]

33. Cardona, C.M.; Li, W.; Kaifer, A.E.; Stockdale, D.; Bazan, G.C. Electrochemical considerations for determining absolute frontier orbital energy levels of conjugated polymers for solar cell applications. Adv. Mater. 2011, 23, 2367-2371. [CrossRef] [PubMed]

34. Azimi, H.; Senes, A.; Scharber, M.C.; Hingerl, K.; Brabec, C.J. Charge Transport and Recombination in Low-Bandgap Bulk Heterojunction Solar Cell using Bis-adduct Fullerene. Adv. Energy Mater. 2011, 1, 1162-1168. [CrossRef]

35. Lu, L.; Kelly, M.; You, W.; Yu, L. Status and prospects for ternary organic photovoltaics. Nat. Photon. 2015, 9, 491-500. [CrossRef]

(C) 2020 by the authors. Licensee MDPI, Basel, Switzerland. This article is an open access article distributed under the terms and conditions of the Creative Commons Attribution (CC BY) license (http://creativecommons.org/licenses/by/4.0/). 